\title{
An Assessment of Availability and Utilization of Laboratory Facilities for Teaching Science at Secondary Level
}

\author{
Ram Babu Pareek* \\ Department of Education in Science and Mathematics, Regional Institute of Education, Ajmer, Rajasthan, India
}

*Corresponding author: pareekrbp@gmail.com

\section{ABSTRACT}

The present study aimed to explore the availability and utilization of a science laboratory for the teaching and learning of science. This study was a joint collaboration with India's Ministry of Human Resource Development, the Government of India, and the National Council of Educational Research and Training. The study adopted descriptive survey methodology and random sampling. The instruments used for the study were questionnaires for principals, teachers, and students. The study's findings revealed in most participating schools; there were no separate science laboratories. It was also found that many teachers faced difficulties when conducting science activities due to the large number of students in each class as well as inadequate equipment and materials. The findings highlight that as there was no assessment of science laboratory practical activities, these activities did not contribute directly to the measurement of students' academic performance in science. The study suggested that governments should support laboratory practical activities in science as a part of assessment and specifically for this study's context takes immediate steps to set up science laboratories in all schools for the effective teaching and learning of science.

KEY WORDS: school science; secondary school science; science teaching; science laboratory`

\section{INTRODUCTION}

$\mathbf{E}$ ducation is generally considered one of the basic needs of human beings. Science has been characterized as a body of knowledge evolved by scientists while science education builds on the knowledge and skills acquired by the learners so that students can understand scientific principles, laws, and theories. The emphasis on teaching and learning of science is on ensuring that teachers not only teach the processes of science but also enable sensory learners to learn scientific concepts. By this, the "hands" and "minds" of leaners must be on scientific activities such that learners will be able to learn actively and thereby participate in knowledge construction (Ausubel, 1963).

The science laboratory has a direct effect on both students' attitudes and academic performance as per the instructional theory of learning interaction. It is generally believed that constant practice leads to proficiency in what the learner learns during classroom instruction; hence, the dictum "practice makes perfect" (Hager, 1974). The quality of teaching and learning experience depends on the extent of the adequacy of laboratory facilities in secondary schools and the teacher's effectiveness in the use of laboratory facilities with the aim of facilitating and providing meaningful learning experiences in the learners. Investigating the relationship between adequacy and academic performance in chemistry, Akpan (2006) examined the adequacy of laboratory facilities using frequency counts and percentages. Lagoke (1997) examined the adequate use of laboratory facilities during science instruction helps to develop values that aid the learners in decision-making. Okeke's (1995) study also examined the adequacy of laboratory facilities and academic performance in basic sciences. This study revealed that the adequacy of laboratory facilities had no significant relationship with students' academic performance in basic science.

The laboratory is a distinctive feature in science teaching and learning. The extent of adequacy of laboratory facilities for science teaching depends on the population of students in a particular school (Hofstein and Ginetta, 1998, Stuckey 2013). I would argue that for students to learn effectively, teachers should ensure that adequate laboratory facilities are provided. It should be noted that in Indian schools it is normal for the teacher and student ratio to be 1:40. What is the affect, if any, of this teacher to student ratio on the teaching and learning process?

Academic performance depicts the level of educational attainment of an individual. It differentiates one with high knowledge content from others with lower and lesser competency in academic performance (Eshiet, 1996). The adequacy of laboratory facilities has been reported to have a significant effect on the students' academic performance in chemistry (Okafor, 2000). However, a study on the influence of the adequacy of laboratory facilities and academic performance in chemistry found that adequacy had a significant influence on students' academic performance in secondary school chemistry teaching (Aburime, 2004). 


\section{RATIONALE OF THE STUDY}

One of the prime aims of the Government of India is the Universalization of Secondary Education (USE), which has resulted in large-scale expenditures in terms of additional schools, classrooms, teachers, and laboratory facilities needed to meet the challenges of providing quality $21^{\text {st }}$ century education (National Council of Educational Research and Training [NCERT, n.d.]). I would argue that any course in science does not show its excellence until it is related to practical work. As, stated, laboratory practical activities, stimulate and motivate students to learn more about science. Student engagement in laboratory courses has shown positive impact on students' achievement in science. A laboratory activity is a way of allowing students to learn with understanding and at the same time engages in a process of constructing knowledge by doing science. In a laboratory activity, students work individually or in small groups on a question, problem, or hypothesis. This hands-on process uses materials of science to construct their own explanation of the scientific phenomena. The distinction between laboratory and traditional classroom learning is that activities are students centered, with students actively engaged in hands-on and minds-on activities using laboratory techniques (Lazarowitz and Tamir, 1994).

India's National Curriculum Framework (NCF) (NCERT, 2005a) observed that schools, particularly those in rural areas, should be equipped with laboratories or equipment for science and mathematical activities. The absence of such facilities drastically narrows subject options for children, denying them equal opportunities for learning and future life chances. While elementary schools can benefit from a science and mathematics corner, secondary schools require well-equipped laboratories.

The position paper brought out by NCERT on teaching of science (NCERT, 2005b) suggested a 2-fold approach to deal with the problem: (i) Encourage practical/technological/ creative components of the curriculum through nonformal channels and (ii) introduce some carefully designed experiments or technology-based questions in the theoretical paper itself. The NCF (2005) also suggested that schools have well-equipped laboratories, libraries, and access to computers, were essential, and all efforts must be made to ensure that schools and junior colleges are well equipped with such resources.

To achieve USE, the Government of India launched the Rashtriya Madhyamik Shiksha Abhiyan (RMSA) programme. Under the RMSA framework, importance has been given to schools to establish laboratories as a part of the strengthening of academic infrastructural facilities. As such, there is a need to identify the importance of laboratories and their utilization in government secondary schools. The present study has been undertaken to identify the laboratory facilities in the selected government secondary schools and their utilization with the following objectives:

- To identify the availability of laboratory facilities for teaching of science

- To study the utilization of available laboratory facilities in teaching of a science

- To study the effect of utilization of laboratory facilities on students' achievement in science

\section{METHODOLOGY AND RESEARCH DESIGN}

The sample of the study was based on stratified random sampling. In the first stage, of the 33 districts of Rajasthan, the three districts of Jaipur, Ajmer, and Nagaur were randomly selected in consultation with the RMSA of Rajasthan. In the second stage, from each of the districts, seven government secondary schools were selected. The study adopted a survey method in which primary data was collected from the principals, teachers, and students belonging to the 21 government secondary schools located in the Jaipur, Nagaur, and Ajmer districts of Rajasthan state using questionnaires and focus group discussions (FGDs). A structured FGD was held in all the schools separately for classes IX and X students (students aged 14-15 years old). The Government of India's programme for USE, RMSA has been under implementation since 2009-10 with the vision to make secondary education of good quality available, accessible, and affordable to all children in the age group of 14-16 years. As such, the age group of 14-15 years was selected. In each group, there were 10-15 students representing each class. Consent letters were collected from RMSA officials, school authorities, and from parents. Faculty members from the Regional Institute of Education, Ajmer, were involved in the collection of data. As per the schedule, the faculty visited the schools, observed the laboratory facilities, and administered separate questionnaires to the principals, teachers, and students.

\section{Tools Used in the Study}

Three tools in the form of questionnaires were developed at NCERT by the RMSA project group involving faculty members from the Regional Institutes of Education Ajmer and Mysuru all the Regional Institutes of Education located across India at Ajmer, Bhubaneswar, Bhopal, Mysuru, and Shillong. The pilot study was conducted in one school of each three randomly selected districts from Rajasthan state. After

Table 1: Availability of laboratory facilities

\begin{tabular}{|c|c|c|c|c|c|c|}
\hline \multirow[t]{3}{*}{ Availability of laboratory facilities } & \multirow{2}{*}{\multicolumn{2}{|c|}{ Principal }} & \multicolumn{4}{|c|}{ Responses } \\
\hline & & & \multicolumn{2}{|c|}{ Teacher } & \multicolumn{2}{|c|}{ Student } \\
\hline & Yes (\%) & No (\%) & Yes (\%) & No (\%) & Yes (\%) & No (\%) \\
\hline & $9(42.85)$ & $12(57.15)$ & $8(33.33)$ & $16(66.67)$ & $15(40.54)$ & $22(59.46)$ \\
\hline
\end{tabular}


receiving constructive feedback from RMSA project group and faculty members from all the Regional Institutes of Education, the study's tools were designed.

\section{Questionnaire for principals}

This questionnaire contained 17 questions, which were both close and open ended. The questions were related to general aspects of the school, number of science teachers, availability of science laboratory, science kit, and provision in the timetable for laboratory-based activities, source of finance, provision for inclusive education, and suggestions for improving the current status.

\section{Questionnaire for teachers}

This questionnaire contained 32 items that were both close and open ended. The questions were related to general information about the teacher, in-service training received, availability and access to curricular materials, provisions made in the curriculum, textbook and timetable for conducting laboratory work, conducting activities venue, nature, involvement of students and guidelines, special arrangement for children with special needs (CWSN), difficulties faced while conducting the activities, mode of the conduct of laboratory work, source of finance, infrastructure, laboratory materials available, and suggestions for improving the science laboratory.

\section{Questionnaire for students}

The questionnaire consisted of 17 questions, which contained both closed- and open-ended items. The questions were related to the availability of laboratory in the school, its utilization, provision for practical in the timetable, process of the conduct of experiments, practice of fine, etc., for breakage of equipment and guidelines for the conduct of the experiments and safety in the laboratory.

\section{DATA ANALYSIS AND INTERPRETATION}

The data were analyzed to address the three purposes of the study. The data were analyzed both quantitatively and qualitatively, i.e., frequency and percentage and content analysis.

The data analysis is provided in two sections: Availability and utilization.

\section{Availability of Laboratory, Curricular Materials, Financial Grant, Infrastructure, and Provision in the Timetable for Experimentation}

A laboratory is expected to be present in every secondary school for the conduct of experiments in science. It was observed that of 21 schools, only one school had a functional science laboratory as mentioned in the Table 1. Only $33.33 \%$ of teachers responded that they had an integrated laboratory for science and mathematics. Principals (57.15\%) responded that most do not have separate laboratories in the schools for science and many students (40.54\%) responded that they did not have laboratories in the schools. It also observed that only $25 \%$ of students used a laboratory once a week and $8 \%$ of students used a laboratory twice a week. Hence, it can be concluded that majority of the schools do not have science laboratory. Therefore, it can be concluded that only one school had a functional science laboratory and most teachers have used integrated laboratory for science and mathematics.

Teaching and learning is always strengthened by referring to curricular materials. Only $25 \%$ of the teachers referred to the NCF. The state of Rajasthan has not developed its own Rajasthan state curriculum framework but follows NCERT textbooks at the secondary level. It was observed that $16.6 \%$ of the teachers had no access to the science syllabus. It was also noted that $50 \%$ of the teachers did not have any opportunity to refer to either supplementary materials or laboratory manuals. As per the NCF 2005 document, both manuals and resources are as important as textbooks for teachers and there is a need for a teacher's handbook as indicated in the Table 2 . These would provide tips for teachers, which they could use for lesson planning. This study identified that only a few of the participating teachers referred to the NCF document and many teachers did not have access to the science syllabus.

\section{Recommendation and Guidelines in the Textbook for Experimentation}

The study further found that teachers usually conduct their science activities in their classrooms (Table 3 ).

When the teachers were asked whether the curriculum document and the textbooks provided scope for experimentation in science, most of the teachers $(67 \%)$ responded that they were expected to conduct experiments in the laboratory/classroom. Some examples that indicated the scope in the textbook for conducting the experiments included: Chemical reaction, oxidation and reduction, and $\mathrm{pH}$ paper experiments.

\section{Table 2: Accessibility of curricular materials}

\begin{tabular}{lcc}
\hline \multirow{2}{*}{ Accessibility of curricular materials } & \multicolumn{2}{c}{ Teacher responses } \\
\cline { 2 - 3 } & Yes (\%) & No (\%) \\
\hline NCF-05 & $6(25)$ & $18(75)$ \\
RSCF & $4(16.6)$ & $20(83.4)$ \\
Syllabus & $20(83.4)$ & $4(16.6)$ \\
Textbook & $13(54.17)$ & $11(45.83)$ \\
Supplementary materials & $12(50)$ & $12(50)$ \\
Laboratory manual & $6(25)$ & $12(50)$
\end{tabular}

NCF: National curriculum framework, RSCF: Rajasthan state curriculum framework

\begin{tabular}{lcc}
$\begin{array}{l}\text { Table 3: Recommendation and guidelines in the textbook } \\
\text { for experimentation }\end{array}$ & Yes (\%) & No (\%) \\
\hline Items/responses & $16(66.67)$ & $8(33.33)$ \\
\hline $\begin{array}{l}\text { Recommendation for experimentation } \\
\text { Provision in the textbooks for conducting } \\
\text { experiments }\end{array}$ & $17(70.83)$ & $7(29.17)$ \\
$\begin{array}{l}\text { Inclusion of guidelines in the textbooks for } \\
\text { conducting experiments/activities }\end{array}$ & $15(62.50)$ & $9(37.5)$ \\
\begin{tabular}{l} 
There is a specific laboratory manual \\
\hline
\end{tabular} & $5(20.83)$ & $19(79.17)$ \\
\hline
\end{tabular}


Table 4: Provision in the timetable for laboratory activities

Provision in the timetable for laboratory activities

Responses

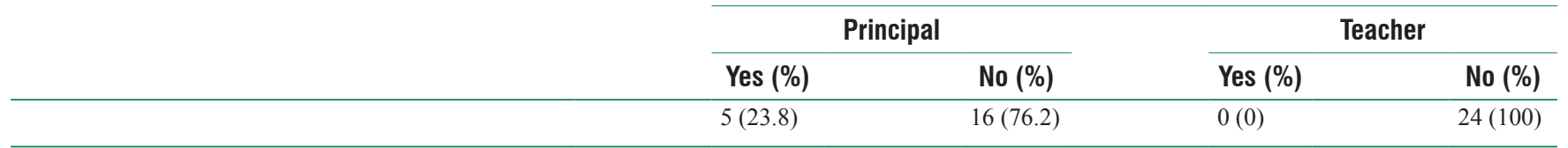

Regarding guidelines in the textbook for conducting experiments, most of the teachers $(62.5 \%)$ responded that there were guidelines in the textbook, whereas nearly $80 \%$ of the teachers responded that there was no specific laboratory manual which they followed for conducting experiments and the rest followed a laboratory manual published by private agencies.

\section{Availability of Financial Grants}

Teachers were asked about the availability and utilization of financial grants for procuring chemicals and replacing the unserviceable equipment in the laboratory. It was noted that only $16.67 \%$ of the teachers had a recurring grant for procuring chemicals and $95 \%$ of the teachers responded that there was no separate grant for replacing the unserviceable equipment in the laboratory. Regarding utilization of the grant, a majority of the teachers $(75 \%)$ responded that the grant was not being properly utilized. The principals of the participating schools expressed a similar opinion. It was reported by the principals that they did not receive grants from RMSA regularly; only $17 \%$ of the principals responded that they did receive grants for meeting the laboratory-related expenses between 2012 and 2014.

\section{Provision in the Timetable for Laboratory Activities}

Learning of science is often based on doing (i.e., hands-on activities); however, none of the participating schools has allotted a separate and specific slot for laboratory activities in their timetable (Table 4).

From Table 4, it could be inferred that these schools have a low priority for providing laboratory activities for students. It was noted that a free period in the timetable could be utilized either for science activities or library work.

Utilization of Laboratory Facilities: Conduct of Experiments/ Activities, Difficulties Faced, Arrangements for CWSN, Effect of Conducting of Experiments, Materials Used for Science Class, and Financial Grant

\section{Conduct of experiments/activities}

The data indicated in the Table 5 regarding conducting of experiments/activities, teachers responded with respect to whether they had made any improvisations to perform activities proposed in the textbooks. Only $37.50 \%$ of the teachers had improvised the activities given in the textbooks which included lime water test for carbon dioxide, iron dust, and a balloon experiment with regard to designing of experiments using locally available materials and $33.33 \%$ of the teachers could design some activities using waste materials and material used in daily life.

In case of conducting experiments involving corrosive chemicals and glassware, teachers were asked to write about
Table 5: Conduct of experiments and activities

\begin{tabular}{|c|c|c|}
\hline \multirow[t]{2}{*}{ Items } & \multicolumn{2}{|c|}{ Teacher } \\
\hline & Yes (\%) & No (\%) \\
\hline Any improvisation in the experiment & $9(37.50)$ & $15(62.50)$ \\
\hline $\begin{array}{l}\text { Devising of experiments using locally } \\
\text { available materials }\end{array}$ & $8(33.33)$ & $16(66.67)$ \\
\hline Guidelines to be given to students & $13(54.17)$ & $11(45.83)$ \\
\hline $\begin{array}{l}\text { Instructions regarding any accident } \\
\text { (if happens) in the laboratory }\end{array}$ & $5(13.52)$ & $32(86.48)$ \\
\hline $\begin{array}{l}\text { Students being allowed to use the equipment } \\
\text { directly }\end{array}$ & $15(62.50)$ & $9(37.50)$ \\
\hline
\end{tabular}

the precautions they took in such cases. This study found that $70 \%$ of participating teachers took precautions while handling the glassware carefully, not disposing of the chemicals/solid waste into the washbasin, and the use of appropriate amounts of chemicals. Regarding guidelines to be given to students for conducting activities, $45 \%$ of the teachers responded that they did not give any guidelines and the remaining teachers responded that they give guidelines.

Regarding precautions to be taken in the case of fire/acid accidents and breakage of glassware, $90 \%$ of the students were never informed about such things by the teachers. Similarly, the way of using the laboratory, only $8 \%$ of the students responded that they go in small groups to the laboratory, whereas $16 \%$ of the students responded that the entire class goes at the same time to the laboratory. With regard to the way the students conduct experiments in the laboratory, only $25 \%$ of the students went in a group of seven or more. However, $90 \%$ of the students never performed any activity individually and they worked in a group of three-six students. With regard to using the equipment/materials in the laboratory, $37 \%$ of the students had used beakers, spirit lamps, concave mirrors, litmus papers, and thermometers and $24 \%$ of the students had used a tripod stand, spring balance, or voltmeter. $51 \%$ of the participating students had used convex lens, microscopes, test tubes, and prisms. While using the materials in the laboratory, there is the possibility of breakage. When students were asked whether they were penalized for such acts, $97 \%$ of the students responded that they were neither asked to pay nor were they punished.

Teachers were asked to name any two activities conducted by them along with the students during the current academic year. The activities named by them were $\mathrm{pH}$ meter test, glass slide experiment in physics, experiments with prism, lens, and mirror and those activities had been conducted using 
demonstration method by $45 \%$ of the teachers and using group activity by $25 \%$ of the teachers. It was also found that $45 \%$ of the teachers responded that the activities were being conducted by demonstration method. $48 \%$ of the students responded that they were being held in the classroom itself. The two demonstrations liked by the students were an onion membrane experiment and acid-base indicator test. Whenever demonstrations were held, $65 \%$ of the students could not see clearly what the teacher was demonstrating and $73 \%$ of the students were of the opinion that teachers did not involve students in the demonstration. Regarding other forms of activities, out of school activity was organized by only $8 \%$ of the teachers and individual experimentation was conducted by $12 \%$ of the teachers.

With regard to students being allowed to use the equipment directly about $70 \%$ of the teachers responded that they were not allowed to use. Only $22 \%$ of the principals stated that laboratory was not being used by secondary stage students. This was true as $73 \%$ of the students had not done any experiment on their own, whereas the rest of the students had performed experiments such as litmus paper, use of $\mathrm{pH}$ paper, and lime water test. When the principals were asked about the alternative arrangements that were made to overcome the problem of non-availability of science laboratory in school, $17 \%$ of them responded that they use higher secondary school laboratory or arrange demonstrations and 30\% of them carried out experiments in the class. It was also found that mobile laboratories were not in the reach of any school as per the response of the principals. It is, therefore, clearly evident that no proper hands-on experience are provided to the students.

\section{Extent of Involvement of Students in Conducting the Activities}

Teachers were asked about the extent of the involvement of students in conducting the activities (Table 6).

While $33.33 \%$ of the teachers had responded that it is high, $20.83 \%$ of the teachers have opined that it is moderate and the remaining (30\%) teachers opined that the involvement of the students has been low.

\section{Difficulties Faced While Conducting the Activities}

As mentioned in the Table 7 activites are normally a part of teaching-learning process. When the teachers were asked about the difficulties they faced while conducting the activities, $41.67 \%$ of the teachers responded that student strength is a problem and $33.33 \%$ of them related to a lack of adequate equipment and materials. It was also found that $45 \%$ of the teachers had the difficulty in getting assistance for setting up of the apparatus.

As per the response of the principals, none of the schools had a laboratory attendant. Therefore, it could be expected that there was some difficulty in using laboratories in schools. As per the response of the principals, $73 \%$ of them responded that they had teachers with biological science backgrounds, whereas $26 \%$ responded that they had teachers with physical science backgrounds. This showed a disproportion of physical and biological science teachers to teach science.

\section{Arrangements for CWSN}

In every school, there may be the possible presence of a child with special needs. As the schools are expected to be inclusive in their set up, it is essential for the schools to have adequate arrangements for catering to the needs of CWSN. Regarding the availability of CWSN in the schools, the majority of the teachers $(80 \%)$ responded that there were not any such children in their classes. All the participating teachers responded that there were not any special arrangements for including CWSN in the laboratory work. This lack of support for CWSN was further strengthened by the responses of the principals, who responded that except for a ramp in one of the schools, no special arrangements were made for CWSN. For most of the participating schools, there were no specific arrangements made for CWSN.

\section{Effect of Conducting of the Activities/Experiments}

Activities and experiments, when performed by students, are intended to develop certain skills among the students. Teachers were asked to state whether the activities conducted by them could result in developing process skills among the students. $70 \%$ of the teachers responded that the activities did result in developing observation skill (Table 8), 12-13\% responded that it developed hypothesizing and interpreting skills, $30 \%$ responded that it developed classifying skill, 9\% responded that it developed predicting skill, and every teacher opined that the activities did not develop inferring skill.

\begin{tabular}{|c|c|c|c|}
\hline \multicolumn{4}{|c|}{$\begin{array}{l}\text { Table 6: Extent of the involvement of students in } \\
\text { conducting the activities }\end{array}$} \\
\hline \multirow[t]{2}{*}{ Items } & \multicolumn{3}{|c|}{ Teacher response } \\
\hline & High & Moderate & Low \\
\hline $\begin{array}{l}\text { Extent of involvement of the students in } \\
\text { conducting the activities }\end{array}$ & 33.33 & 20.83 & 30.00 \\
\hline
\end{tabular}

Table 7: Difficulties faced by teachers while conducting science activities

Problems/difficulties

High student strength

Teacher's response in \%

Lack of adequate equipment and material

41.67

Getting assistance in setting up of the

apparatus

Inadequate duration of laboratory period

33.33

45.00

45.00

Table 8: Effect of conducting of activities/experiments

\begin{tabular}{lc} 
Type of skill developed & Teacher's response in \% \\
\hline Observation skill & 70.00 \\
Hypothesizing and interpreting skills & $12.00-13.00$ \\
Classifying skill & 30.00 \\
Predicting skill & 9.00 \\
Inferring skill & 0.00 \\
\hline
\end{tabular}


With regard to the influence of activities/experiential learning/ virtual laboratories in enhancing science learning among the students, most of the teachers $(62 \%)$ responded that they have enhanced the learning of students in science and their examples include Newton's law and the reflection of light. Nevertheless, $67.5 \%$ of students felt that the laboratory work did not help them to learn science any better. When teachers were asked whether the number of computers available was adequate to give the experience of virtual laboratories, only $41 \%$ of the teachers responded that the number of computers was sufficient. While examining the student computer ratio in the class, it varied from $1: 3$ to $1: 50$. While it was $1:<10$ in eight schools, it was 1:>13 in six schools. This indicates a poor student-computer ratio in schools.

Teachers were asked whether the students were encouraged to participate in exhibitions and other science-related activities. While $50 \%$ of the teachers responded yes, they did encourage and around $21 \%$ of the teachers responded that the laboratories were not equipped enough to help students to prepare models for exhibitions and other science-related activities. Even $73 \%$ of students expressed that they were not encouraged to use laboratory equipment for project works. This indicates poor furnishing of laboratories to undertake activities.

\section{Other Materials Used for Science Class}

It is the responsibility of the teacher to make science interesting to the students as well as effective. For this purpose, teachers could use other materials apart from laboratory resources. While $67 \%$ of the teachers responded that they used science kits, $95 \%$ of the principals responded that they did have science kit in their schools. It was noted that $30 \%$ of the principals stated that the equipment was not adequate to teach all the children in the school even though $17 \%$ of the principals responded that the teachers in their schools received training in laboratory skills. $30 \%$ of the principals responded that the teachers in their schools had received training in using science kits. For making classes interesting and effective, $46 \%$ of the teachers responded that they used models and $17 \%$ of the teachers said that they use CDs/audio-visual (AV) materials.

\section{Utilization of Financial Grant}

Although financial grant is available for purchasing chemicals, $80 \%$ of the teachers were of the opinion that the grant received was not used appropriately. Even $78.26 \%$ of the principals have said that the fund was not being used for improving laboratory resources. This shows that although there is availability of grant in many of the schools, it was not being utilized appropriately.

\section{RESULTS OF THE STUDY}

An integrated laboratory for science was available only in $33 \%$ of the schools. Only $25 \%$ of the teachers had access to the NCF 2005 document and laboratory manual, whereas $75 \%$ of the teachers had access to a science syllabus. In addition, $50 \%$ of the teachers had access to supplementary materials to teach science. In India, teachers are expected to conduct experiments in the laboratory as per the curriculum and the guidelines given in the textbook. To support this, recurring grants are available to most of the schools for procuring the chemicals, but there is no separate grant for replacing the equipment that is broken/malfunctioning. None of the schools' timetables gave a dedicated space for a separate slot for laboratory activities. A free period for students was being utilized for either laboratory activities or library work. About $33 \%$ of the teachers tried to improvise the apparatus for performing science activities given in the textbooks. It should be noted that safety precautions were taken by the majority of teachers while handling hazardous chemicals. Similarly, guidelines given by the teachers were followed by all the students. This study highlighted that most of the schools did not allow students to use the equipment directly and in many schools, students had not conducted the experiments on their own. Involvement of the students in conducting the activities was appreciably low. Teachers faced the problem of student numbers (class sizes of greater than 40 students) in their classroom as in the Indian context teacher it is normal for teachers to have a student ratio of 1:40. Similarly, teachers face issues of inadequate equipment, no assistance for setting up apparatus, and inadequate duration of laboratory period in conducting the activities. There were no special arrangements in any of the schools for including CWSN in the laboratory work and they had never performed any special laboratory activity either for them or with them.

The activities conducted by the students resulted in the development of their observation skills to a large extent, then classifying, predicting, and interpreting to some extent. There was no development of inferencing skills at all. Most of these participating schools noted that the student-computer ratio was very high and laboratories were not equipped well enough to conduct activities. More importantly for this study, in most of the schools, experiments were not conducted. For making their teaching and learning in science effective, only a few of the participating teachers used science kits, models, and compact discs/AV materials. For breakage of laboratory materials, students were neither fined nor punished. In most of the schools, financial grant meant for laboratories was not used appropriately.

\section{CONCLUSION}

The study investigated the adequacy of science laboratory facilities for effective teaching and learning of science in 21 secondary schools from the Rajasthan state, India. Findings of this study showed that laboratory facilities are highly inadequate, far below the expectation, and in most of the schools, science experiments are not being conducted. This study also revealed that as there is no assessment of science practical activities, it does not contribute directly to the measurement of students' academic performance in science.

It is important that resources are made available for establishing laboratories with adequate facilities in schools. It is, therefore, recommended that the Indian government should include 
practical activities in science as a part of the formal assessment procedures and take immediate steps to equip/set up science laboratories for the effective teaching and learning of science. It is also suggested to facilitate science teachers being more resourceful by providing support materials for science teaching and learning so that students learn by doing, develop thinking skills, and attempt innovations.

\section{REFERENCES}

Aburime, E.F. (2004). Refocusing Research Technology and Mathematics Education: A Case for Mathematics Laboratory. Akure: Proceeding of the $45^{\text {th }}$ Annual Conference of Science Teachers' Association of Nigeria.

Akpan, O. (2006). Laboratory Facilities for Chemistry Teaching. Unpublished Seminar Paper. Nigeria: University of Calabar.

Ausubel, D. (1963). The Psychology of Meaningful Verbal Learning. New York: Grune and Stratton.

Eshiet, I.T. (1996). Improvisation in Science Teaching Philosophy and Practice. Abak: Belpot Press.

Felder, R.M., \& Prince, M.J. (2006). Inductive teaching and learning methods: Definitions, comparisons, and research bases. Journal of Engineering Education, 95, 123-138.

Hager, W.R. (1974). An investigation of verbal behaviour and learning climate in undergraduate engineering classroom. Journal of Research in Science Teaching, 11(2), 121-131.
Hofstein, A., \& Ginetta, A. (1998). Trends in Assessment of Laboratory Performance in Secondary Schools in Instruction. Iowa: University of Iowa Press.

Lagoke, B.A. (1997). Toward an elimination of the gender gulf in science concept attainment through the use of environment analogs. International Journal of Science Education, 9(4), 365-367.

Lazarowitz, R., \& Tamir, P. (1994). Research on using laboratory instruction in science. In: Gabel, D.L., (Ed.), Handbook of Research on Science Teaching and Learning, New York: Macmillan. pp. 94-130.

NCERT. (2005a). National Curriculum Framework 2005. New Delhi, India: NCERT.

NCERT. (2005b). National Focus Group on Teaching of Science 2005. New Delhi, India: NCERT.

NCERT. Universalization of Secondary Education in India Vision. Available from: http://www.ncert.nic.in/departments/nie/dse/deptt/activities/pdfs/ chapter_1.pdf. [Last retrieved on 2019 Jan 15].

Okafor, P.N. (2000). Difficult concepts in physics as experienced by senior secondary students in Akwa Ibom State. Journal of Research Information in Education, 1(1), 114-121.

Okeke, R.J. (1995). Principles of development selection, utilization, evaluation storage and retrieval of instructional materials. In: Okwo, F.A., \& Ike, G.A., (Eds.), Educational Technology: Basic Concepts of Issues. Nsukka: University Trust Publishers. pp. 45-76.

Stuckey, M., Hofstein, A., Mamlok-Naaman, R., \& Eilks, I. (2013). The meaning of 'relevance' in science education and its implications for the science curriculum. Studies in Science Education, 49, 1-3. 